\title{
POWER CONSUMPTION OPTIMIZATION FOR BREAD DOUGH PROVER
}

\author{
Adriana Istudor, Gheorghe Voicu, Gheorghe Muscalu, Mariana Munteanu \\ University Politehnica of Bucharest, Romania \\ istudor.adriana@mgbiotech.ro,ghvoicu_2005@yahoo.com,munteanumaya@yahoo.com
}

\begin{abstract}
The final proofing of wheat dough takes place in enclosed spaces called provers, in which temperature and relative humidity are controlled. The purpose of this paper is to analyse the possibility of reducing the power consumption necessary for prover air conditioning by replacing the thermal agent (heated with methane gas) with recovered energy from the burnt gases released on the evacuation tunnel during baking. In the first part of the paper the necessary power was calculated for: heating the air in the prover and the interior structure up to 33 ${ }^{\circ} \mathrm{C}$; the losses through the prover walls and the necessary power for raising the dough's temperature to $6{ }^{\circ} \mathrm{C}$. The second part of the paper contains real time measurements for power consumption in three stages: at the starting point; after reaching the set parameters; with load. In the last part of the paper a comparative analysis of power consumption before and after mounting an energy recovery system on the evacuation tunnel for burnt gases of a bread oven is presented. The obtained results showed less than $5 \%$ differences between the calculated and measured values. To ensure the set parameters for a $216 \mathrm{~m}^{3}$ prover, with an hourly capacity of 4000 dough pcs*0.36 kg, the prover consumes: $27 \mathrm{~kW}$ in the first hour of functioning (without load), $14 \mathrm{~kW}$ after reaching the set parameters and $20 \mathrm{~kW}$ when working fully loaded. The results obtained after using the energy recovery system showed $55 \%$ reduction of power consumption using conventional fuel.
\end{abstract}

Keywords: dough, proofing, energy, recovery, air-conditioning.

\section{Introduction}

The dynamics and intensity of dough proofing are influenced by the flour properties, dough composition, technological process and proofing parameters; these factors are interdependent. The fermentation process takes place only if there are optimal conditions regarding the nutrition environment and the microclimate parameters [1]. For example, excessive proofing can produce sticky doughs with low viscosity, which are difficult to handle and also represents unnecessary cost to the bakeries [2]. The parameters necessary for good control of the proofing process are the proofing time, temperature and relative humidity. In most industrial bread making processes the proofing time varies between 40 and 90 minutes, and the proofing parameters are: $30-35^{\circ} \mathrm{C}$ and $70-85 \%$ relative humidity [3]. The relative humidity varies directly with temperature and air distribution speed inside the proofing chamber. The values must be chosen so as to avoid or limit humidity losses from the loaves to the environment, which affects the product quality [1].

The main parameters characterizing the air in the ventilation field are: temperature, humidity, specific weight, specific heat, enthalpy [4;5]. Optimal air conditioning parameters in a bread prover are ensured using air conditioning units, which prepare the air with temperature and humidity and distribute it inside the prover, using the air vent and distribution pipes. The basic elements, which compose an air conditioning unit, are: water heat and cold exchanger, flow ventilator with the frequency variation unit, which establishes the recirculated air flow.

Obtaining higher thermal efficiency in every technological area should be a priority. It is estimated that up to $50 \%$ of industrial energy input is wasted [6-8]. Usually the economic efficiency overshadows the energy efficiency when it is reffered to industrial manufacturers $[9 ; 10]$, but the energy recovery systems are a viable solution for reducing conventional fuel usage with multiple positive effects. Currently, heat exchangers are considered to be the best systems for recovering the waste heat energy $[11 ; 12]$.

\section{Materials and methods}

The energy recovery system with thermal tubes used in this research is mounted on the burnt gas evacuation pipe of a tunnel bread oven and uses up to $10 \%$ of the burner capacity. It recovers heat to obtain hot water, which can be used for air conditioning units or other amenities.

In Figure 2 the materials are shown used to measure the power consumption necessary for prover air conditioning in three stages: at the starting point; for constant keeping the temperature in range and after it was fully loaded with dough. The thermo-anemometer was used to measure the air speed in the air distribution system $[13 ; 14]$. 

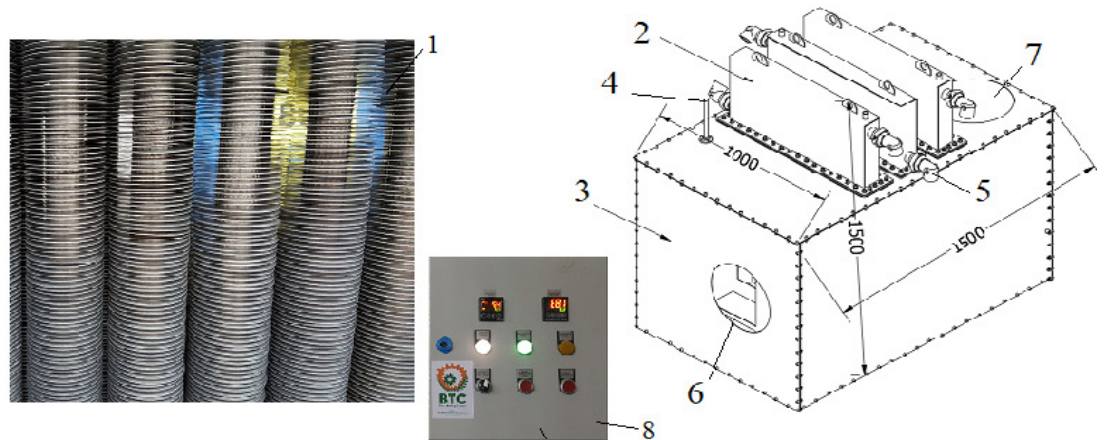

Fig. 1. Energy recovery system [15]: 1 - thermal tube; 2 - superior boxes; 3 - metallic structure; 4 - overheating protection; 5 - pipes; 6 - burnt gas entering; 7 - burnt gas release; 8 - automation box

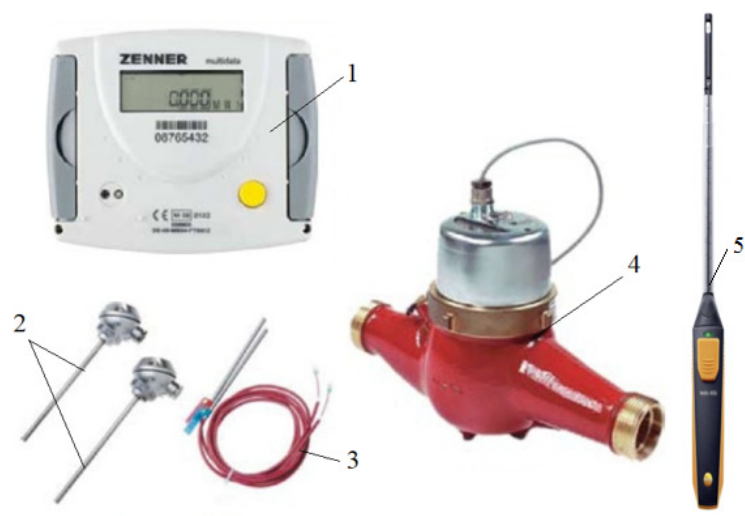

Fig.2. Equipment used [13; 14]: 1 - thermal energy calculator, kW; 2 - Pt 100 type probes; 3 - Pt 500 probes; 4 - reader flow meter; 5 - Bluetooth thermo-anemometer

The algorithm presented in this research was used to determine: the necessary air and humidity flow to raise the temperature in a 4 stories tunnel prover, with 4000 dough pcs $\cdot 0.36 \mathrm{~kg} \cdot \mathrm{h}^{-1}$ capacity, with $8{ }^{\circ} \mathrm{C}$ and $20 \% \mathrm{RH}$; the air flow necessary to maintain a constant set temperature and to heat the prover's structure plus losses; the air flow necessary to raise the temperature in the piece dough to $6{ }^{\circ} \mathrm{C}$.

The initial parameters were considered: temperature $t_{1}=25^{\circ} \mathrm{C}$, relative humidity $\varphi_{1}=55 \%$. Final proving parameters were: mean air temperature $t_{f}=33{ }^{\circ} \mathrm{C}$, relative humidity, $\varphi_{f}=75 \%$. For reaching and maintaining these parameters the following was considered: recirculating air temperature, $t_{2}=40^{\circ} \mathrm{C}$, and relative humidity, $\varphi_{2}=75 \%$. The air flow value used in the algorithm was $Q=2200 \mathrm{~m}^{3} \cdot \mathrm{h}^{-1}$, with air mean speed $v=2 \mathrm{~m} \cdot \mathrm{s}^{-1}$ and a working pressure of $p=1013 \mathrm{mbar}$.

The general relation for enthalpy $(h)$, based on absolute air humidity $(x)$, is written as, $[4 ; 16]$ :

$$
h=c_{p a} t+x\left(r_{v}+c_{p v} t\right), \mathrm{kJ} \cdot(\mathrm{kg} \text { dry air })^{-1}
$$

where specific dry air heat $c_{p a}=1.004 \mathrm{~kJ} \cdot \mathrm{K}^{-1}$;

water vaporizing latent heat at $0{ }^{\circ} \mathrm{C}$ is $r_{v}=2500 \mathrm{~kJ} \cdot \mathrm{kg}^{-1}$;

specific heat of overheated water vapours $c_{p v}=1.863 \mathrm{~kJ} \cdot \mathrm{K}^{-1}$.

The Dalton law can be used to determine the vapour quantity reported to air dry quantity $(x)$ :

$$
x=\frac{m_{v}}{m_{a}}=\frac{M_{v} \cdot p_{v}}{M_{a} \cdot p_{a}}=\frac{0.622 \cdot p_{v}}{p-p_{v}}, \mathrm{~kg} \text { vapours } \cdot(\mathrm{kg} \text { dry air })^{-1}
$$

and

$$
p_{v}=\varphi \cdot p_{s}, \text { bar }
$$

where molar mass for water vapours $M_{v}=1.016 \mathrm{~kg} \cdot \mathrm{mol}^{-1}$;

molar mass for dry air $M_{a}=28.97 \mathrm{~kg} \cdot \mathrm{mol}^{-1}$; 
$m_{v}-$ water vapours mass;

$m_{a}-$ air dry mass;

$p_{v}$ - partial pressure of vapours and has the values $p_{v 1}=17.419$ mbar,

and $p_{v 2}=55.313$ mbar, respectly;

$p s$ - vapours saturation pressure (tabled, at $25^{\circ} \mathrm{C}, p_{s 1}=31.67$ mbar and $p_{s 2}=73.75 \mathrm{mbar}$ at $\left.45^{\circ} \mathrm{C}[16]\right)$.

The obtained values for the vapour quantity reported to air dry quantity $(x)$ for $\varphi_{1}=55 \%$, and $\varphi_{2}=75 \%$ are: $x_{1}=0.011 \mathrm{~kg}$ vapours $\cdot(\mathrm{kg} \text { dry air })^{-1}$ and $x_{2}=0.036 \mathrm{~kg}$ vapours $\cdot(\mathrm{kg} \text { dry air })^{-1}$, respectly. The specific enthalpies for humid air are: $h_{1}=52.813 \mathrm{~kJ} \cdot \mathrm{kg}$ dry air ${ }^{-1}$ and $h_{2}=132.648 \mathrm{~kJ} \cdot(\mathrm{kg} \operatorname{dry} \text { air })^{-1}$.

The heat and humidity flow is determined with $[4 ; 16]$ :

$$
\begin{gathered}
\dot{Q}=\dot{m} \cdot \Delta h, \mathrm{~W} \\
\dot{G}=\dot{m} \cdot \Delta x, \mathrm{~kg} \cdot \mathrm{s}^{-1}
\end{gathered}
$$

The mass air flow circulated by an installation, $\dot{m}, \mathrm{~kg} \cdot \mathrm{s}^{-1}$ is calculated with $[4 ; 18]$ :

$$
\dot{m}=\rho \cdot v \cdot A,
$$

where $\quad v=2 \mathrm{~m} \cdot \mathrm{s}^{-1}$;

$A$ - pipe section surface, $A=0.09 \mathrm{~m}^{2}$;

$\rho, \mathrm{kg} \cdot \mathrm{m}^{-3}-$ humid air density and it is inversely proportional with the humid air mass volume.

$$
V=R_{a} \cdot \frac{T}{p \cdot(1+x)} \cdot\left(1+x \cdot \frac{R_{v}}{R_{a}}\right), \mathrm{m}^{3} \cdot \mathrm{kg}^{-1}
$$

where $\quad R_{a}$ - characteristic constant of dry air, $R_{a}=287.14 \mathrm{~J} \cdot \mathrm{kg} \cdot \mathrm{K}^{-1}$;

$R_{v}$ - characteristic constant of water vapours, $R_{v}=461.915 \mathrm{~J} \cdot \mathrm{kg} \cdot \mathrm{K}^{-1}$;

$T$ - final temperature $\left(t_{f}=40{ }^{\circ} \mathrm{C}\right), T=313.15 \mathrm{~K}$;

$x=0.036 \mathrm{~kg}$ vapours $\cdot(\mathrm{kg} \text { dry air })^{-1}$ for $\varphi_{2}=75 \%$; therefore, $\rho=1.103 \mathrm{~m}^{3} \cdot \mathrm{kg}^{-1}$ and the mass air flow is $\dot{m}^{\prime}=0.199 \mathrm{~kg} \cdot \mathrm{s}^{-1}$.

The heat flow necessary for heating the metallic structure is [4]:

$$
\dot{Q}_{\text {structure }}=\frac{m \cdot c_{O L} \cdot \Delta t}{\tau}, \mathrm{W}
$$

where $c_{O L}=0.63 \mathrm{~kJ} \cdot \mathrm{kg} \cdot \mathrm{K}^{-1}$ is the specific heat of steel;

interior structure temperature $i s t_{i s}=25^{\circ} \mathrm{C}$,

set temperature is $t_{f s}=33{ }^{\circ} \mathrm{C}$;

limit time is $\tau=3600 \mathrm{~s}$.

To determine heat losses through the walls the following area surfaces were considered: $A_{1}=A_{2}=L \cdot h=72 \mathrm{~m}^{2} ; A_{3}=A_{4}=L \cdot l=72 \mathrm{~m}^{2} ; A_{5}=A_{6}=l \cdot h=9 \mathrm{~m}^{2} ;$ the total surface area $A_{\text {wall }}=234$ $\mathrm{m}^{2}$ and floor area, $A_{\text {floor }}=72 \mathrm{~m}^{2}$.

The global thermal transfer coefficient $\mathrm{k}$ is calculated using [4]:

$$
k=\frac{1}{\frac{1}{a_{\mathrm{int}}}+\frac{\delta}{\lambda}+\frac{1}{a_{\text {ext }}}}, \mathrm{W} \cdot \mathrm{m}^{-2} \cdot \mathrm{K}^{-1}
$$

where $\lambda$-panel's thermal coefficient;

$\lambda=0.027 \mathrm{~W} \cdot(\mathrm{m} \cdot \mathrm{K})^{-1}$;

superficial thermal transfer coefficient $\alpha_{\text {int }}, \alpha_{\text {ext }}=0.29$;

the thickness of the panels $\delta=0.1 \mathrm{~m}$.

The global heat transfer through the walls and floor has the following formula [4]:

$$
\dot{Q}=k \cdot A \cdot \Delta t, W
$$




\section{Results and discussion}

Fig. 3 presents power consumption registered in all three analyzed stages by a thermal energy calculator connected to the air conditioning system.

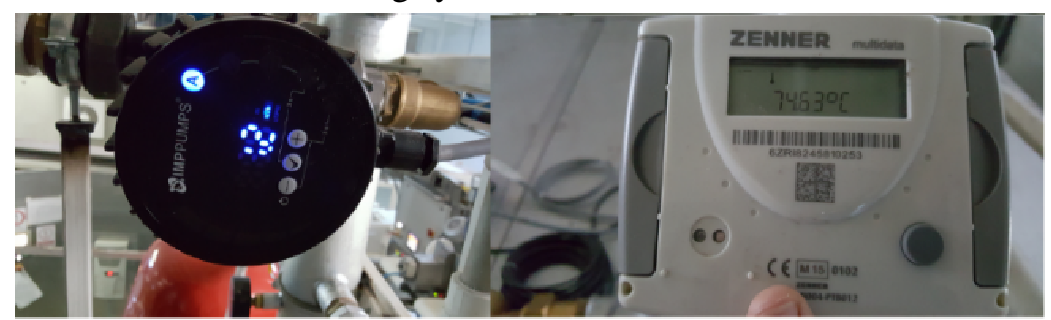

a)

b)

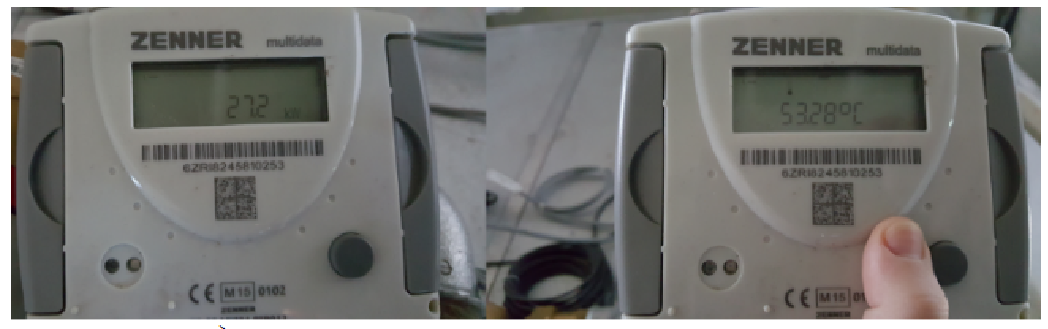

c)

d)

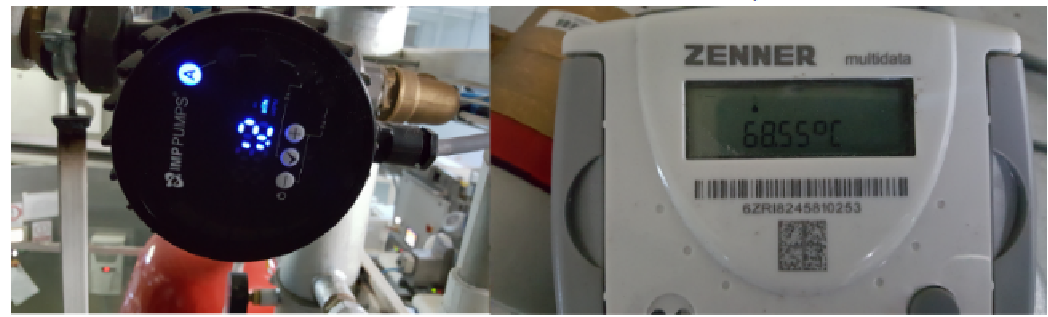

a)

b)

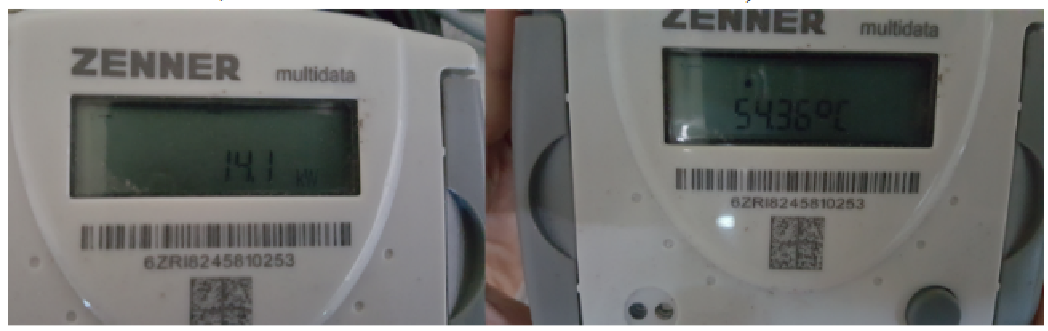

c)

d)

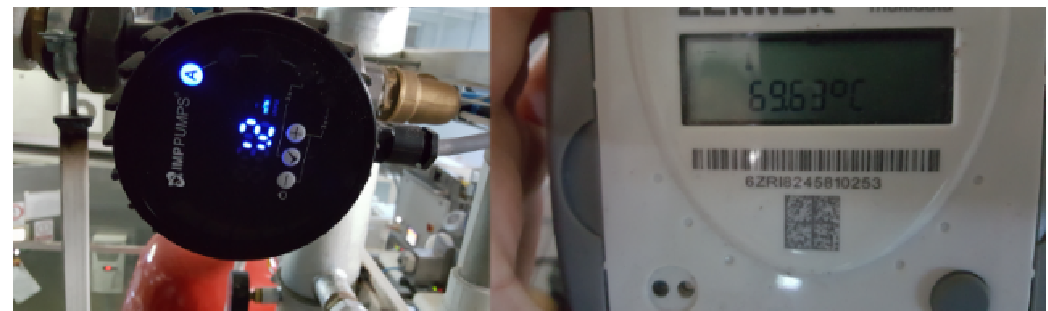

a)

b)

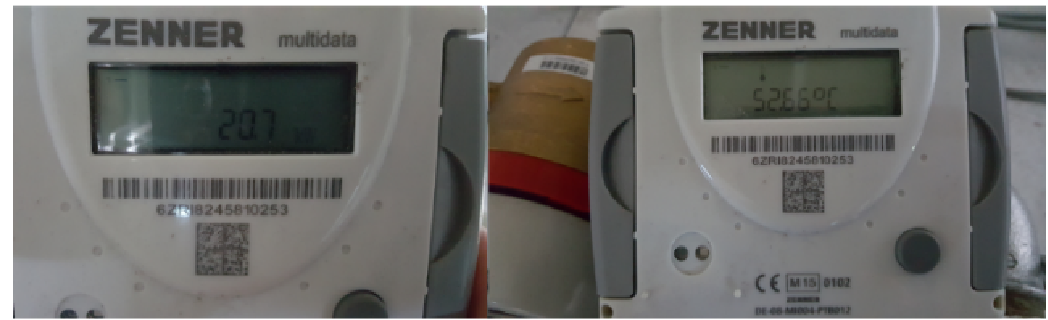

c)

d)

Fig. 3. Prover power consumption: first image - first hour of functioning; second image - in range parameters maintenance; third image - working cycle with proofing dough 
In Figure 3, a) is the hot water flow, b) is the input temperature for the air conditioning system, c) is the power consumption registered in real time by the thermal energy calculator and d) is the output temperature for the air conditioning system.

The determined values for the power consumption necessary to ensure optimal parameters in a prover for a 20 hour working cycle are: prover heating- $15.85 \mathrm{~kW}$; metallic structure heating- $10.5 \mathrm{~kW}$; wall losses- $0.29 \mathrm{~kW}$; floor losses- $0.1 \mathrm{~kW}$; total consumption for the first hour- $26.7 \mathrm{~kW}$; maintaining temperature setpoint and structure- $12.79 \mathrm{~kW}$; dough temperature increase with $6{ }^{\circ} \mathrm{C}-4.56 \mathrm{~kW}$; hourly necessary for continuous working- $17.35 \mathrm{~kW}$; steam consumption in the first hour-12.06 kW; steam consumption for continuous working- $8 \mathrm{~kW}$. The obtained values were compared with real measurements of power consumption for ensuring the necessary parameters of temperature and relative humidity in a 20 hour working period.

Figure 4 shows the comparative analysis between the determined and measured power consumption for all three stages of working.

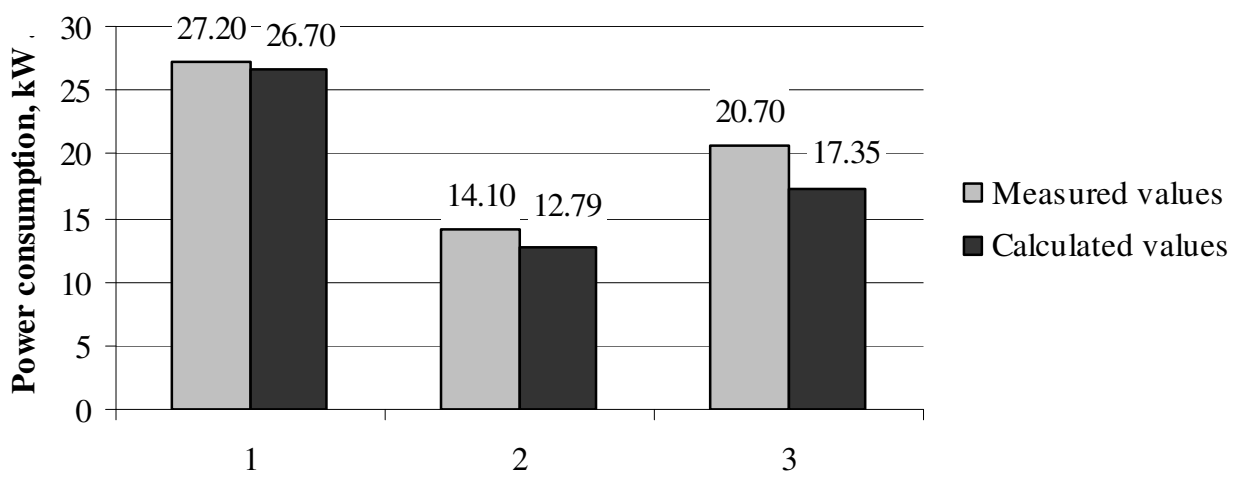

Fig. 4. Comparative analysis between determined and measured power consumption

Table 1 presents a comparative analysis between the air conditioning system, which uses conventional and recovered energy, respectly. The analysis was performed for a 20 hour production cycle, with a $4000 \mathrm{pcs} \cdot 0.36 \mathrm{~kg} \cdot \mathrm{h}^{-1}$. The recovered energy reduced the conventional energy consumption by $55 \%$. It is necessary to specify that the measurements were performed as follows: in the first hour of functioning, the heating power was provided entirely by the central heating, until the temperature of the burnt gases could provide the recovery system with enough energy. Starting with the next hour, the prover functioned only using the recovery system.

Table 1

Standard vs. recovered energy consumption for ensuring prover parameters

\begin{tabular}{|c|c|c|c|c|c|c|c|c|}
\hline \multirow[b]{2}{*}{$\begin{array}{c}\text { Production } 20 \\
\mathrm{~h} \cdot \text { day }^{-1}\end{array}$} & \multicolumn{8}{|c|}{ Energy consumption } \\
\hline & $\begin{array}{l}\text { Conventi } \\
\text { onal, } 1 \mathrm{~h} \text {, } \\
\mathrm{kWh}\end{array}$ & $\begin{array}{l}\text { Steam } \\
1 \mathrm{~h}, \\
\mathrm{kWh}\end{array}$ & $\begin{array}{c}\text { Conventional, } \\
19 \mathrm{~h}, \mathrm{kWh}\end{array}$ & $\begin{array}{c}\text { Steam, } \\
19 \mathrm{~h}, \\
\text { kWh }\end{array}$ & $\begin{array}{c}\text { Cooling } \\
1 \mathrm{~h}, \\
\mathrm{kWh}\end{array}$ & $\begin{array}{c}\text { Cooling } \\
19 \mathrm{~h}, \\
\mathrm{kWh}\end{array}$ & $\begin{array}{l}\text { TOTA } \\
\mathrm{L}, \mathrm{kWh}\end{array}$ & $\begin{array}{l}\text { Month, } \\
\text { kWh }\end{array}$ \\
\hline Standard & 27.2 & 12 & 393.3 & 152 & 4.5 & 85.5 & 718.2 & 21546 \\
\hline $\begin{array}{l}\text { With } \\
\text { recovery }\end{array}$ & 27.2 & 12 & 0 & 152 & 4.5 & 85,5 & 324.9 & 9747 \\
\hline
\end{tabular}

\section{Conclusions}

Energy recovery system integration in the functioning logic of the air conditioning system offers the possibility of obtaining higher thermal efficiency and considerable decrease of conventional energy consumption.

The analysis perfomed in this research showed the power consumption necessary for ensuring the optimal proofing parameters for a cycle of $20 \mathrm{~h}$, in three working stages and the values obtained showed significant differences.

For the first hour of functioning (without load considered), the power consumption to raise the temperature parameter, alongside the structure temperature, losses considered, was $26.7 \mathrm{~kW}$ calculated and 27.2 measured. For ensuring the humidity setpoint, $12 \mathrm{~kW}$ consumption is necessary. 
For the second stage, meaning temperature range maintenance, the structure temperature and losses included, $12.79 \mathrm{~kW}$ power consumption is necessary. The measured value was $14.1 \mathrm{~kW}$, the difference between the values can be explained through other losses in the proving system, probably due to time ware. For maintaining the humidity value, $8 \mathrm{~kW}$ are consumed.

For the third stage, the necessary power consumption was determined and measured for raising the temperature in dough pieces, with 6 degrees, from $27^{\circ} \mathrm{C}$ to $33{ }^{\circ} \mathrm{C}$ at the end of the proofing time. The power consumption for this stage alone was $4.56 \mathrm{~kW}$. Adding this value to the power consumption necessary for ensuring the second stage, the power consumption for a 19 hour working cycle is $17.35 \mathrm{~kW}$ calculated and $20.7 \mathrm{~kW}$ measured.

The results obtained in this research showed $55 \%$ decrease in conventional energy consumption necessary for ensuring optimal parameters in a 4 stories tunnel prover with a $4000 \mathrm{pcs} \cdot 0.36 \mathrm{~kg} \cdot \mathrm{h}^{-1}$ production capacity.

In further research it is hoped to create comparisons between the power consumption of other prover types.

\section{References}

[1] Istudor A., etc. Final bread dough fermentation - requirements, conditions, equipment. A short review, International Symposium, INMA-TEH, Bucharest, 2017, pp. 519-526;

[2] Sinelli N. Casiraghi E. Downey G. Studies on proofing of yeasted bread dough using near- and midinfrared spectroscopy. J Agric Food Chem. Vol 56, 2008, pp. 922-931;

[3] Burluc R. M.. Technology and quality control in bread making industry, Galati, 2007. Available at: http://www.scribd.com;

[4] Gheorghe D. etc. Manualul de instalații, Instalații de ventilare și climatizare, (Instalations manual, Venting and conditioning instalations), Artenco Publishing House, Bucharest, 2002, p.457. (In Romanian);

[5] Dry and humid air notions, Online Course, Gheorghe Asachi Technical University of Iaşi, Romania. [online][12.04.2019] Available at: https://www.academia.edu/28703786/Capitolul_2_Notiuni_de_aer_uscat_si_umed

[6] O'Rielly K., Jeswiet J.Improving industrial energy efficiency through the implementation of waste heat recovery systems, Transactions- Canadian Society for Mechanical Engineering, 2014, vol. 39, pp.125-136;

[7] Waste Heat Recovery: Technology and Opportunities in U.S. Industry, United States Department of Energy, Industrial Technologies Program, 2008;

[8] Energy Efficiency Guide for Industry in Asia. United Nations Environment Programme, Division of Technology, Industry, and Economics, 2006;

[9] Chiaroni D., Chiesa V., etc. Introducing a new perspective for the economic evaluation of industrial energy efficiency technologies: an empirical analysis in Italy. Sustain Energy Technol Asses, vol.15, 2016, pp.1-10;

[10] Wolley E., Luo Y., Alessandro S. Industrial waste heat recovery: a systematic approach, Sustainable Energy Technologies and Assesments, vol.29, 2018, pp. 50-59;

[11] Kaushik S., Reddy V., Tyagi S. Energy and exergy analyses of thermal power plants: a review. Renew Sustain Energy Rev, vol.15, 2011, pp. 1857-1872;

[12] Khodami R, Abbas Nejad A, Ali Khabbaz M. Experimental investigation of energy and exergy efficiency of a pulsating heat pipe for chimney heat recovery. Sustain Energy Technol Asses., vol.16, 2016, pp: 7-11;

[13] Contor Zenner multidata. [online][12.04.2019] Available at: http://www.calorserv.ro/files/products/documents/wr1.pdf/wr1.pdf.

[14] Thermo-anemometer. [online][12.04.2019] Available at: https://www.germanelectronics.ro.

[15] Biotehnologicreativ manufacturer, Romania. [online][12.04.2019] Available at: https://biotehnologicreativ.ro/

[16] Conditioning and ventilation installations, Online Course, Ovidius University of Constanta, Romania. [online][12.04.2019] Available at: http://idd.univovidius.ro/tutorials/cursuri/FIM/ING9/09Climatizare.pdf. 